\title{
Bedload transport for heterogeneous sediments
}

\author{
Marine Durafour ${ }^{1}$ - Armelle Jarno ${ }^{1}$ - Sophie Le Bot ${ }^{2}$ - Robert Lafite $^{2}$ - François Marin ${ }^{1}$ \\ ${ }^{1}$ UMR CNRS 6294 LOMC, 53 Rue Prony, 76600 Le Havre, France. \\ Marine DURAFOUR : marine.durafour@doct.univ-lehavre.fr ( $\square$ ) \\ Armelle JARNO : jarnoa@ univ-lehavre.fr \\ François MARIN : francois.marin@univ-lehavre.fr $(\square)$ \\ 2 UMR CNRS 6143 M2C, Bat. IRESE A, Place E.Blondel, 76821 Mt-St-Aignan, France. \\ Sophie LE BOT : sophie.lebot@univ-rouen.fr \\ Robert LAFITE : $\underline{\text { robert.lafite@ univ-rouen.fr }}$
}

\begin{abstract}
A large panel of instruments was deployed in the Eastern English Channel to measure the evolution of bedload fluxes during a tidal cycle for two different sites. The first one was characterized by a sandy bed with a low dispersion in size while the other study site implied graded sediments with grain sizes ranging from fine sands to granules. The in-situ results obtained were compared with predictions of total bedload fluxes by classical models. A good agreement was found for homogeneous sediments with these formulas. In the case of size heterogeneous sediments, a fractionwise approach, involving a hiding-exposure coefficient and a hindrance factor, provided better predictions of bedload fluxes, but still some discrepancies were noticed. Present results revealed that the consideration of particle shape in formulas through the circularity index enhanced the estimations of bedload transport rates. A new adjustment of Wu et al.'s (2000) formula was proposed and a very good agreement was obtained between the measured and predicted values.
\end{abstract}

Keywords Bedload transport - Grain shape - Sediment mixtures · In-situ measurements · Coastal zone

\section{Introduction}

Bedload sediment transport in the coastal area is a dynamic process mainly influenced by sediment heterogeneity (i.e. size, density and particle shape) and the intensity of hydrodynamic forcings (current and/or waves). As a major issue for sedimentologists and engineers for beach erosion, refill of dredged areas or scouring of offshore structures, numerous studies have been carried out to better understand this process.

Balasubramanian et al. [2], Chu et al. [6] or Rousseaux et al. [34] among others, studied the impact of oscillatory flows on sediment sorting during bedload transport for ripple beds. Meyer-Peter and Muller [26], Brown [5], Einstein [11], Engelund and Hansen [12], Van Rijn $[43,45]$ or Nielsen [28] not exhaustively, allowed to estimate of total bedload rates under a current alone excitation for uniform granulometries. At this end, they used a single fixed representative bed-material size, usually the $50 \%$ sieve diameter $\mathrm{D}_{50}$. Some formulae like the ones proposed by Meyer-Peter-Muller [26], Van Rijn [43,46] or Ribberink [32] have been adapted to compute fractional sediment fluxes in non-uniform environment by considering the interactions between particles of different sizes in a flow. On the other hand, several investigators as Parker [30], Wu [50] and Wilcock \& Crowe [49] have directly developed their formulation for a multiple-fraction approach. 
Most of the derived equations rely upon laboratory or in-situ data in alluvial channels and are then relevant only for the range of particle sizes and flow conditions from which they were tested. Even if these models are widely used in their actual form, Engelund and Hansen (1967) stated that some sediment properties like shape and gradation received too little attention, which could contribute to explain the differences usually observed between measured and predicted values of bedload fluxes.

In these formulas, an excess shear stress between the Shields parameter given by $\theta=$ $\mathrm{u} * 2 /\left((\mathrm{s}-1) \mathrm{gD}\right.$ and its critical value $\theta_{c r}$ for sediments motion is considered. When the dimensionless shear stress $\theta$ exceeds the critical value $\theta_{c r}$, grains movement is initiated.

A single-fraction approach (SF) is often considered to estimate total bedload rates, but the use of a single sediment size ( $\left.\mathrm{D}_{50}\right)$ appears questionable [27,38]. Thus, a multiple-fraction approach (MF) is generally advised and considers the proportions of each size classes in the bed material. The mixing of particles is taken into account with a hiding-exposure factor $[10,19,50]$ introducing that coarse particles are easier entrained than if there were no finer grains, and small particles are more difficult to move due to the presence of coarse grains. Total fluxes are deduced from an addition of all the fractional fluxes.

Particle shape is also recognized to be a significant factor in the hydrodynamic behavior of grains but as the mechanisms are not fully understood, this parameter is not implemented in bedload transport formulations. Only few studies until now have investigated the behavior of different particle shapes from laboratory measurements [18,20,24] or field observations [21,34,36]. Komar and $\mathrm{Li}[20,24]$ found that elongated grains are more imbricated than spherical particles and thus, less exposed to the flow. Consequently, the value of the Shields number required for their initiation of motion was five to six times larger than for spheres or ellipsoidal pebbles. Allen [1] worked on bivalve shells, analyzing the evolution of the drag coefficient according to different elongations. His results showed that the drag increases with the elongation of shells, limiting their capacity to be transported compared to spherical particles. Smith and Cheung [39,40] showed the strong impact of grain shape on fall and critical velocity. Mantz [25], Prager et al. [31], Paphitis et al. [29] also conducted studies close to the threshold of initial motion for irregularly shaped particles but they have not provided data in higher transport stages. Demir [8] observed a preferential transport of spherical particles but only in extreme conditions during winter storm events with pebbles of diameters ranging from 32 to $128 \mathrm{~mm}$. Finally, Durafour et al. [9] carried out a preliminary study of the influence of particle shape on bedload fluxes in a coastal area. However, very few data were considered and no conclusion could be deduced for the improvement of the existing formulas.

The present study aims to estimate the bedload transport for graded sediments and to analyze if particle shape can partly explain the differences observed between predicted and measured fluxes. At this end, a new set of measurements have been carried out along a tidal cycle on two sites in the Eastern English Channel. The first one is characterized by well sorted sediments on the bed, and the second one by heterogeneous sediments. A panel of innovative in-situ instruments is used to collect bed material samples as well as bedload discharges samples. We compare the in-situ total bedload fluxes obtained (section 4.1) to results of classical equations among the most commonly used in a SF approach (section 4.2) and then refine the calculations with a MF approach (section 4.3). Finally, we focus on the effect of particle shape on bedload fluxes in a fractionwise approach and a new proposition of modification of the fractional formula of $\mathrm{Wu}$ et al. [50] by adjunction of a discriminating shape factor is presented (section 4.4). 


\section{Field sites}

The Eastern English Channel is a semi-enclosed coastal sea, located between England and France, usually considered as a transition between the Atlantic Ocean and the North Sea. Characterized by a gradual slope of the seabed with depths not exceeding 60 meters, its width varies from $35 \mathrm{~km}$ to $140 \mathrm{~km}$. Tides in the Eastern English Channel are semi-diurnal, with a period of $12 \mathrm{~h} 24$, and represent the dominant hydrodynamic forces. The tidal range can reach ten meters during spring tides with strong associated tidal current velocities going up to $1.7 \mathrm{~m} . \mathrm{s}^{-1}$ near the bottom (Velegrakis [47]).

For the present study, two sites are investigated, at equinox spring tide conditions, during a sea campaign called "Mesflux11". The first site, noted $A$, is situated at the latitude $50^{\circ} 04.993$ ' $\mathrm{N}$ and the longitude $1^{\circ} 02.969$ 'E with a mean low water level of 17 meters during measurements. The second area $(B)$ is located at $27 \mathrm{~km}$ South-West of A and at $13 \mathrm{~km}$ off the coastline. At a latitude of $49^{\circ} 58.963^{\prime} \mathrm{N}$ and a longitude of $0^{\circ} 43.125^{\prime} \mathrm{E}$, the mean water depth at low tide on this second study site is of 26.4 meters. The position of both sites is highlighted on Fig. 1.

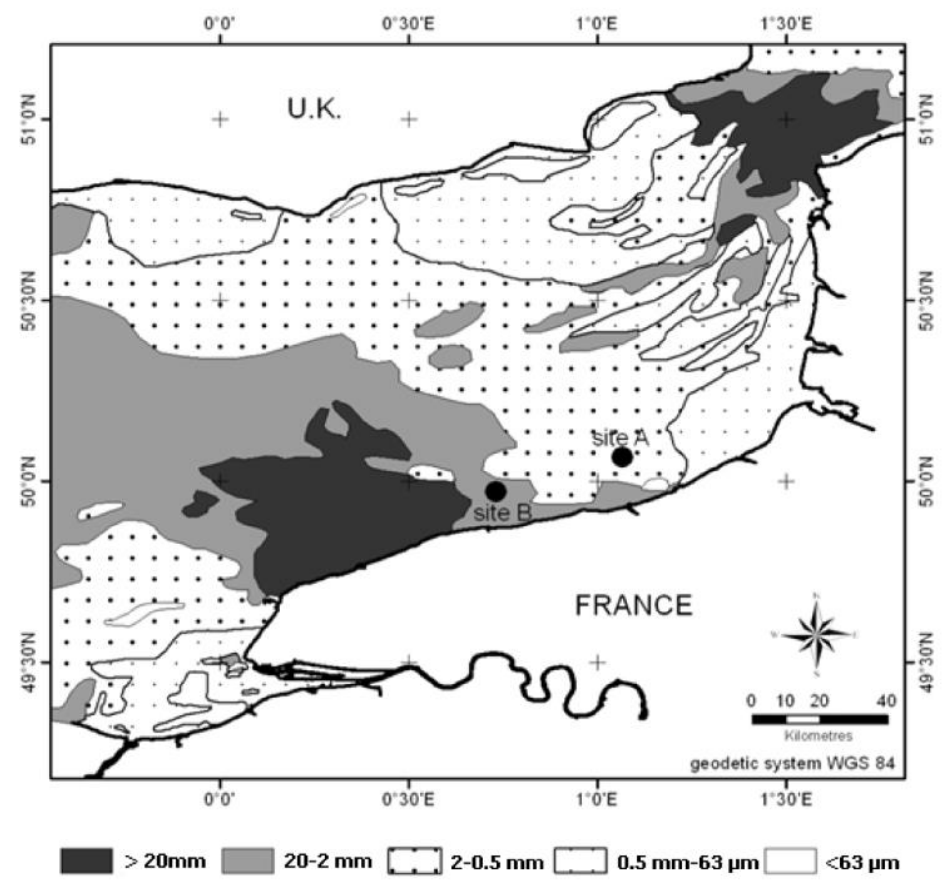

Fig. 1 Generalized distributions of superficial sediments in the Eastern English Channel with locations of the two study sites (after Larsonneur et al. [22] - Scale: 1 / 500 000)

In both areas, the seabed is flat and composed of sand-gravel particles essentially made of blunt and subangular quartz grains and shell debris. The slight difference in sediment density between the siliceous detrital fraction $\left(\rho_{\mathrm{s}}=2.65 \mathrm{~g} / \mathrm{cm}^{3}\right)$ and the carbonate bioclastic fraction $\left(\rho_{\mathrm{s}}\right.$ between 2.6 and $2.8 \mathrm{~g} / \mathrm{cm}^{3}$ ) does not allow to study the specific influence of this parameter. While site A shows a predominance of coarse and very coarse sand from 0.5 to $2 \mathrm{~mm}$ diameter, $\mathrm{B}$ is recognized as being in a more heterogeneous area composed of sand-gravel mixtures with a strong presence of gravels from 2 to $20 \mathrm{~mm}[15,22]$. Finally, in addition to tidal forces, the Eastern English Channel can be exposed to swell with significant wave heights reported by Cotton et al. [6] ranging from 0.5 to $1.5 \mathrm{~m}$. However, during the Mesflux11 campaign, swell had a maximum height of $30 \mathrm{~cm}$, which has no influence on bedload transport considering the depths on each site. 


\section{Description of field measurements}

A large panel of instruments was deployed on both sites during the Mesflux11 campaign. Bed sediment samplings were realized by divers and by using a Shipeck grab sampler. Samples of bedload discharges were then collected with the Delft Nile Sampler shown in Fig. 2a. Hydrodynamic conditions near the bottom are obtained from an Acoustic Doppler Velocimeter (ADV) and the sediment mobility is visualized with the dynamic sediment profile imager developed by Blanpain et al. [3,4] (Fig. 2b).

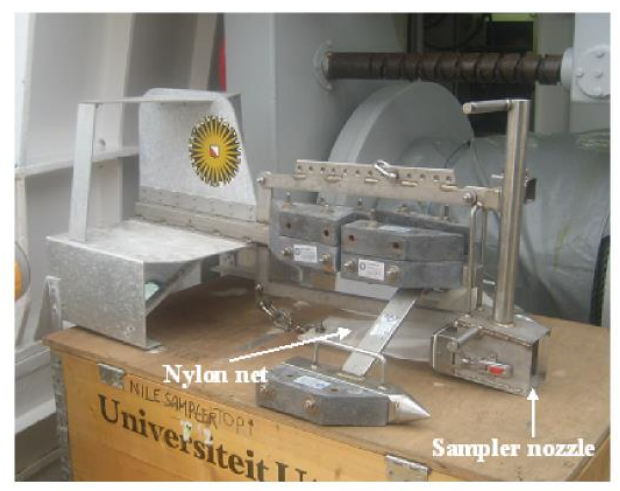

(a)

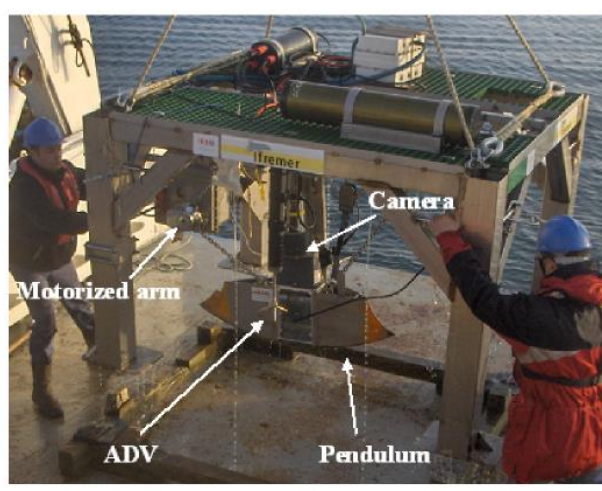

(b)

Fig. 2 The Delft Nile Sampler (a) and the Dynamic Sediment Profile Imager system (b)

\subsection{Bed sediments samples}

To analyze the granulometry of sediments for the $A$ and $B$ sites, two methods were used to collect samples of the bed. The first method used a Shipeck grab sampler that cuts the sediment on fifteen centimeters depth and recovers a sampling volume of around $4 \mathrm{dm}^{3}$. As this method greatly disturbs the sample, another one was used to preserve the sediment by strata in order to visualize a possible vertical sorting. Thus, a metal U-shaped frame was embedded in the sedimentary cover by divers to collect samples of $2 \mathrm{~cm}$ thick on ten centimeters depth of sediments. Each sample was washed, dried and finally sorted on a sieving column ranging from $63 \mu \mathrm{m}$ to $20 \mathrm{~mm}$ respecting the ISO-3310 norm. Sediment size distributions obtained by these two methods are compared in Fig. 3. 
(a)

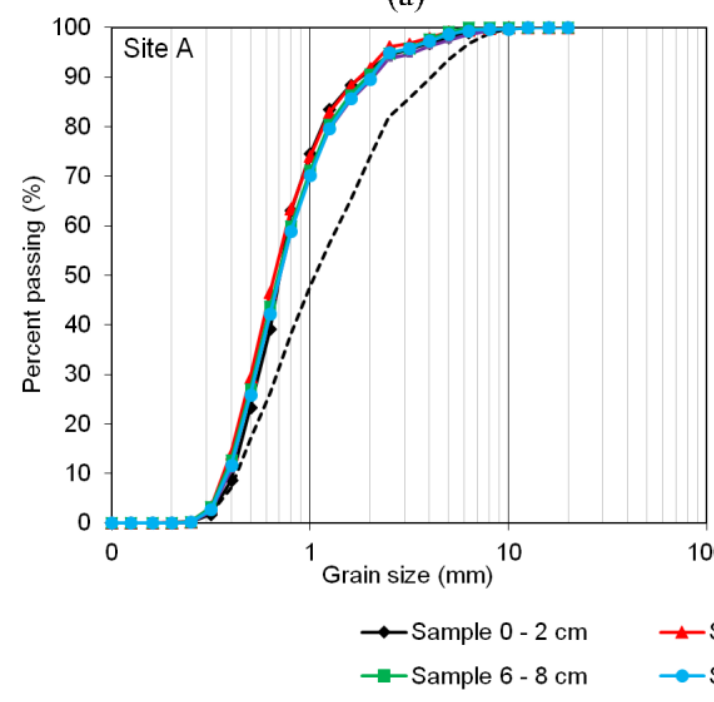

(b)

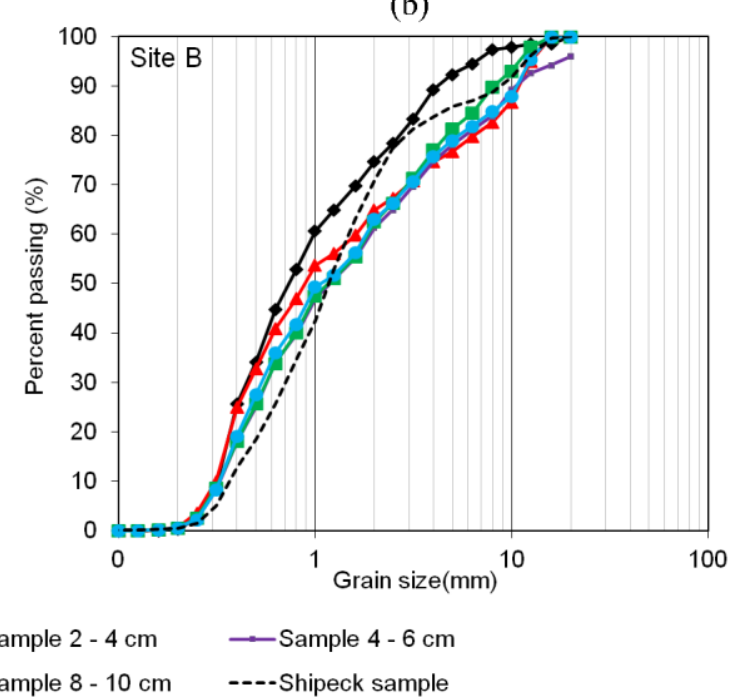

Fig. 3 Sediment size distribution from the Shipeck samples (dotted line) and bed samples recovered by divers before bedload measurements: site A (a); site B (b)

Following the approach of Hirano [14], the seabed is divided in two layers: an active layer of a few centimeters depth, in which the particles interact directly with the flow, and an inactive substrate. In this formulation, the grain size distribution of the bed material displays a discontinuity at the interface between the two layers. In the present study, the analysis of bed sediment samples provides information about the active layer thickness.

The geometric standard deviation of Soulsby [41], $\sigma_{\mathrm{g}}=\sqrt{ }\left(\mathrm{D}_{84} / \mathrm{D}_{16}\right)$ is calculated for each bed sample on both sites. The granulometry is considered as very well sorted if $\sigma_{\mathrm{g}}{ }^{2}<2$ and as widely dispersed if $\sigma_{\mathrm{g}}{ }^{2}>16$. Results are summarized in Table 1 .

Table 1 Geometric standard deviation of bed sediment samples granulometries

\begin{tabular}{|l|cc|}
\cline { 2 - 3 } \multicolumn{1}{c|}{} & \multicolumn{2}{c|}{$\sigma_{\mathrm{g}}{ }^{2}$} \\
\hline Sample name & "A" site & "B" site \\
\hline Divers 0-2cm & 2.9 & 9.3 \\
Divers 2-4cm & 2.9 & 24.9 \\
Divers 4-6cm & 3.4 & 21.0 \\
Divers 6-8cm & 3.2 & 16.0 \\
Divers 8-10cm & 3.3 & 20.0 \\
Shipeck 0-15 cm & 5.8 & 9.0 \\
\hline
\end{tabular}

Considering the samples collected by divers, the geometric standard deviation of site A is close to the one of a well sorted sandy bed $\left(\sigma_{\mathrm{g}}{ }^{2}<2\right)$. Consequently, in the following sections, this site will be assimilated to a uniform environment from the seabed surface to ten centimeters depth. A negligible vertical sorting is observed and the Shipeck sample is not well sorted, meaning that the interface between the active layer and the substrate is located between ten centimeters and the maximum depth reached by the Shipeck grab sampler (15 $\mathrm{cm})$. Unlike the A site, the B site displays a strong heterometric facies and a clear interface at two centimeters depth defining the limit of the active layer. For the site A, only $10 \%$ of the surface layer is composed of gravels from $2 \mathrm{~mm}$ to a maximum of $8 \mathrm{~mm}$ diameter. On site $\mathrm{B}$, a major fraction of sands from $63 \mu \mathrm{m}$ to $2 \mathrm{~mm}(75 \%)$ compose the active layer of the bed with minor fractions of granules between $2 \mathrm{~mm}$ and $4 \mathrm{~mm}(22.3 \%)$ and pebbles beyond $4 \mathrm{~mm}$ 
diameter $(2.7 \%)$.

\subsection{Bedload samples}

In order to investigate the different sizes and shapes of particles transported by bedload, a system called "Delft Nile Sampler" (DNS) was used (Fig. 2a). Initially developed by Gaweesh and Van Rijn [13,44] for a fluvial domain, the use of the DNS on $A$ and $B$ sites was consistent as swell was negligible. This instrument consists of a sampler nozzle of $9.6 \mathrm{~cm}$ wide by $5.5 \mathrm{~cm}$ high, connected to a nylon net meshed at $150 \mu \mathrm{m}$. Positioned on the seabed for a duration of 8 to 13 minutes according to the considered measurement, face to the current, the DNS retrieved regularly the bedload discharges on both sites along a tidal cycle. Total and fractional bedload sediment fluxes, $\mathrm{q}_{\mathrm{s}}$ and $\mathrm{q}_{\mathrm{s}, \mathrm{i}}$ respectively, are determined by using the formulation established by Gaweesh and Van Rijn [13]:

$$
\begin{aligned}
& q_{\mathrm{s}, \mathrm{i}}=\frac{\mathrm{G}_{\mathrm{i}}}{\rho_{s} b t} \\
& q_{\mathrm{s}}=\sum q_{\mathrm{s}, \mathrm{i}}
\end{aligned}
$$

where $G_{i}$ is the mass of sieve residues for the size class $i, t$ the sampling period, $b$ the width of the sampler mouth and $\rho_{s}$ the sediment density $\left(\rho_{s}=2650 \mathrm{~kg} / \mathrm{m}^{3}\right)$. The dimensionless bedload transport is deduced from Eq. 3 and 4.

$$
\begin{aligned}
& \boldsymbol{\Phi}_{\mathrm{b}, \mathrm{i}}=\frac{\mathrm{q}_{\mathrm{s}, \mathrm{i}}}{\sqrt{(s-1) g D_{i}{ }^{3}}} \\
& \boldsymbol{\Phi}_{\mathrm{b}}=\frac{\mathrm{q}_{\mathrm{s}}}{\sqrt{(s-1) g D_{50}{ }^{3}}}
\end{aligned}
$$

In Eq. 3 and 4, $\mathrm{s}$ is the relative density of the sediment, $\mathrm{g}$ is the gravitational acceleration, $D_{i}$ is the median diameter of the considered size class according to the classification of Wentworth [48] and $\mathrm{D}_{50}$ is the median diameter of the entire sample.

\subsection{Dynamic sediment profile imaging (DySPI)}

The DySPI, designed by Blanpain et al. [3,4], is a pendulum whose movement into the sediment is activated by the triggering of a motorized arm (Fig. 2b). During the launching, the DySPI descends in the water column with the rocker in a raised position. Once placed on the bottom, the motorized arm gives a slight circular motion to the pendulum that enters into the sediment from 8 to $15 \mathrm{~cm}$ depth and is stopped by a solenoid switch indicating that the arm is in contact with the frame and is vertical.

A high definition digital video camera (Sony HVR-A1E) is mounted on the DySPI frame, perpendicularly to the seabed, to get top view videos of the study area with a resolution of $1080 \times 1440$ pixels. A one hour mini DV tape is placed in the camera and movies of few minutes are remotely triggered by the onboard computer at regular time intervals. During the Mesflux11 campaign, the DySPI provided approximately two minutes of videos each quarter hour, allowing us to visualize the evolution of the in-situ sediment mobility along a tidal cycle. 
Flow velocity measurements were carried out with a Nortek Vector Acoustic Doppler Velocimeter mounted on the DySPI frame. The central transducer emits a pulse of sound with a frequency of $8 \mathrm{~Hz}$ and the three others measure the phase shift of the echo, providing the directional components of the current velocities $\left(\mathrm{u}_{\mathrm{x}}, \mathrm{u}_{\mathrm{y}}, \mathrm{u}_{\mathrm{z}}\right)$ in a sampling volume of $0.8 \mathrm{~cm}^{3}$. Once the DySPI positioned on the bottom, the ADV provides current velocity measurements at $14 \mathrm{~cm}$ above the seabed. The ADV is coupled to sensors located in its end bell, recording variations in water depth and temperature at the rate of flow velocities.

The velocities modules $U$ are calculated with: $U=\sqrt{u_{x}^{2}+u_{y}^{2}+u_{z}^{2}}$, but the directional component $u_{\mathrm{z}}$ was negligible during measurements. Bed shear velocities $u_{*}(t)$ are deduced from the logarithmic velocity law (Eq. 6) which is relevant in this study as swell is negligible (section 2) and the flow is fully turbulent according to the Reynolds number $R e$ ranging from $1.5 \times 10^{5}$ to $2 \times 10^{7}$ during measurements.

$$
\begin{gathered}
R e=\frac{U h}{v} \\
\mathrm{U}(\mathrm{z}, \mathrm{t})=\frac{u_{*}(t)}{\mathrm{K}} \ln \left(\frac{\mathrm{z}}{\mathrm{z}_{0}}\right)
\end{gathered}
$$

$\mathrm{h}$ is the water depth and $v$ is the kinematic viscosity estimated at $1.4 \times 10^{-6} \mathrm{~m}^{2} / \mathrm{s}$ (Sündermann, [42]) by taking into account the conditions of temperature and salinity during the Mesflux 11 campaign $\left(7.6^{\circ} \mathrm{C}\right.$ and $33.6 \mathrm{ppt}$ based on an average on both sites). In Eq. $6, \mathrm{~K}$ is the Von Karman constant $(\mathrm{K}=0.4), \mathrm{z}$ is the height of the measurement point above the bed $(0.14 \mathrm{~m})$ and $\mathrm{z}_{0}$ is the roughness length estimated with the formulation of Soulsby [41] for transitional flows.

$$
\mathrm{z}_{0}=\frac{v}{9 u_{*}}+\frac{\mathrm{k}_{\mathrm{s}}}{30}\left[1-\exp \left(\frac{u_{*} \mathrm{k}_{\mathrm{s}}}{27 v}\right)\right] \text { with } 70>\frac{\mathrm{k}_{\mathrm{s}} u_{*}}{v}>5
$$

Following the recommendation of Kleinhans and Van Rijn [19], we consider the equivalent bed roughness $\mathrm{k}_{\mathrm{s}}=\mathrm{D}_{75}$.

The accuracy of the obtained values for $\mathrm{u}^{*}(\mathrm{t})$ is assessed by comparing them to Mars $3 \mathrm{D}$ (Model for Application at Regional Scale) predictions, provided by the French Naval Hydrographic and Oceanographic Service (SHOM). This software, developed by IFREMER, is a finite difference model based on the incompressible Navier-Stokes equations [23]. The Mars3D model has been validated in our work area with a maximum relative error of $30 \%$ between measured and numerical data [17]. As the measured velocities lie within this range of efficiency for both sites, our estimation of the bed shear stress is considered as accurate.

During the present measurements, the mean tidal range was $9.05 \mathrm{~m}$ (Fig. 4) and the current direction was alternating. The rising tide lasted in average 5:09 hours, with current velocities directed towards the East-North-East. The ebb tide was longer (7:12 hours), generating currents moving in the West-South-West direction with velocities weaker than the flood ones (Fig. 4). The DNS samples were collected on a rising tide for the A site and during rising and ebb tides for the $\mathrm{B}$ site. The maximum current velocity during bedload transport measurements with the DNS was $0.59 \mathrm{~m} / \mathrm{s}$ for the A site and $0.87 \mathrm{~m} / \mathrm{s}$ for the B site. 


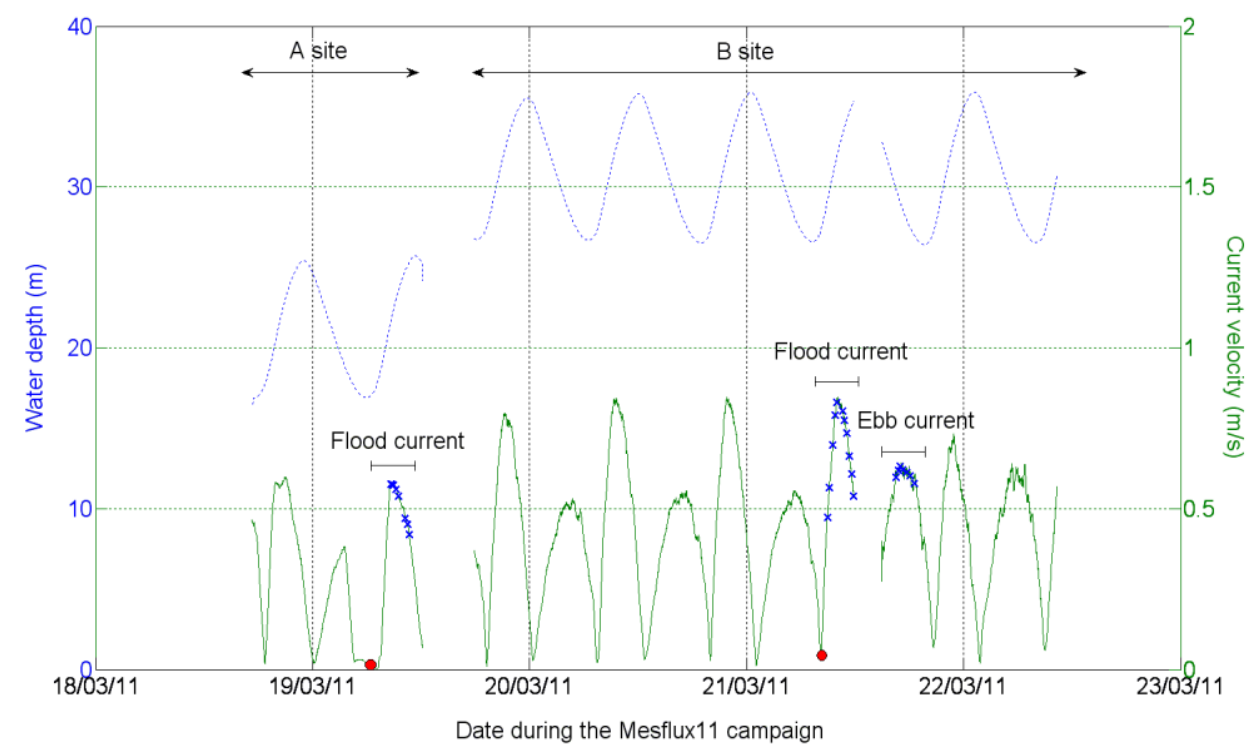

Fig. 4 Temporal evolution of the water depth (dotted lines) and current velocities (solid lines) during measurements on sites A and B. The instants at which bed sediment samples were collected by divers and with a Shipeck grab sampler are shown by two solid circles. The sampling times with the Delft Nile Sampler are depicted by crosses

\section{Results}

\subsection{The existence of "threshold effects"}

Total bedload rates were estimated with sieve residues of DNS samples according to Eq. 1-2. The results on B site during the rising tide displayed some unexpected values, as illustrated by Fig. 5, which shows the temporal evolutions of total bedload fluxes and current velocity. Each dash on the flow velocity curve depicts the instants at which bedload samples were taken.

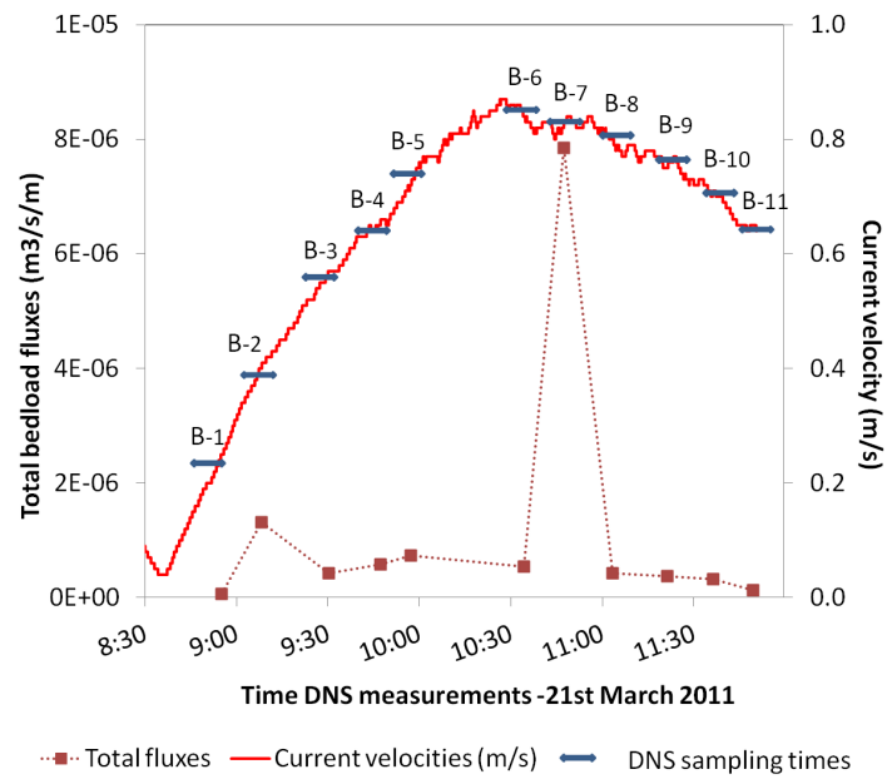

Fig. 5 Total bedload transport rates for site B 
Two measurements of total bedload fluxes (B-2 and B-7 in Fig. 5) are distinct from the other experimental results. The total bedload rate from sample B-2 is approximately 2.5 times higher than the flux expected by following the trend of the measurements shown in Fig. 5. The sample noted B-7 exhibits fluxes 14 times higher than the B-6 sample which was collected for close current velocities. In order to understand the origins of the differences obtained, we used DySPI videos to observe the sediment motions at the bed during the considered rising tide. The camera mounted on the DySPI registered two minutes of videos each quarter hour. The instrument was deployed close to the DNS and the dimensions of the visible area were approximately $30 \mathrm{~cm} \times 25 \mathrm{~cm}$.

The granulometry of the B site (Fig. 3) shows essentially a sand-gravel mixture with some granules and pebbles. For grains moved by the current, the value of the Shields parameter [37] has to be greater than a critical value which can be estimated with the formula of Soulsby [41].

$$
\begin{gathered}
\theta_{\mathrm{cr}, 50}=\frac{0.3}{1+1.2 \mathrm{D}_{*, 50}}+0.055\left(1-\exp \left(-0.02 \mathrm{D}_{*, 50}\right)\right) \\
\mathrm{D}_{*, 50}=\left(\frac{(\mathrm{s}-1) \mathrm{g}}{\gamma^{2}}\right)^{\frac{1}{3}} \mathrm{D}_{50}
\end{gathered}
$$

From the measured values of the current velocity, we can estimate the bed friction velocity $\mathrm{u} *$, the bed shear stress $\tau_{\mathrm{b}}=\rho \mathrm{u} *^{2}$ and the Shields parameter $\theta_{50}=\mathrm{u} *^{2} /\left((\mathrm{s}-1) \mathrm{gD} \mathrm{D}_{50}\right)$. It results that no particle greater than $3.15 \mathrm{~mm}$ in diameter should be displaced by the flow for present tests on the B site. However, we can see in the recorded videos in rare cases some pebbles in motion bigger than this critical size. The corresponding images show that these movements, probably facilitated by the protrusion of pebbles among finer sediments on the bed and by possible unstable positions, induce a destabilization of the surrounding grains, suddenly exposed to the flow. This event results in a significant local increase of bedload transport. Let us call this type of event a "threshold effect". Such a typical event is illustrated in Fig. 6, where two pictures depict the bed area just before and during the displacement of a $40 \mathrm{~mm}$ diameter pebble. The threshold effect presented is representative of bedload transport peaks observed in Fig. 5.

Following the method described in Blanpain et al. [4], we carried out an estimation of total bedload rates from DySPI video records, by converting sequences of two seconds of videos into fifty pictures of $1080 * 700$ pixels resolution. The first image is considered as a reference frame to which is subtracted the following pictures using the ImageJ software. Using an intensity cut-off, we obtain pictures of the total area where sediments move between the instants corresponding to the reference image and to the subsequent ones (Fig. 6c and Fig. $6 d)$. 
(a)

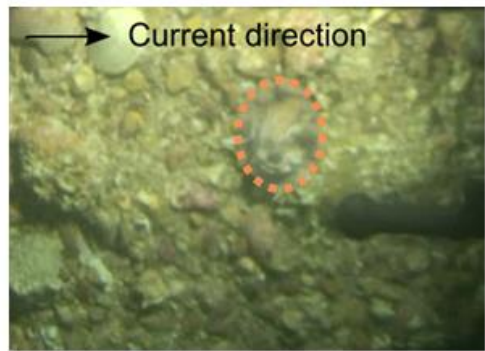

(c)

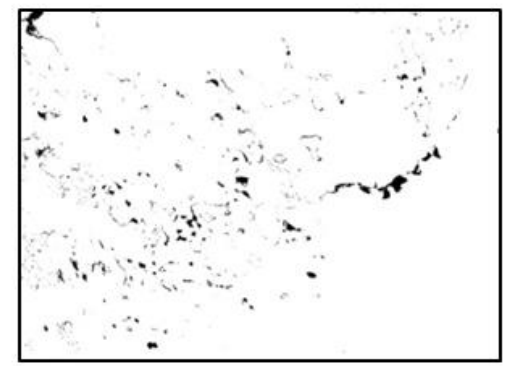

(b)

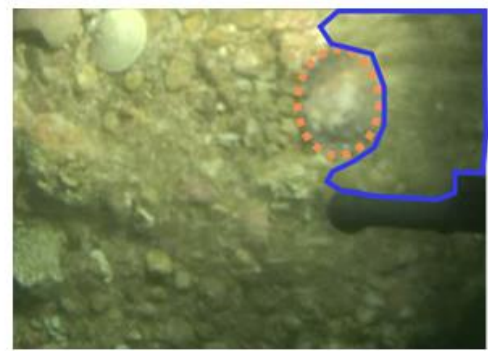

(d)

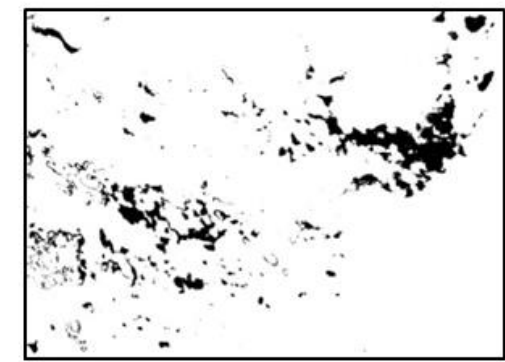

Fig. 6 Threshold effect: picture of the seabed just before (a) and during (b) a threshold event (1 second after the image shown in (a), $U=0.74 \mathrm{~m} / \mathrm{s}$ ). The pebble which has moved is localized by an orange dotted line and the destabilized area by a blue solid line. Grains in motion just before (c) and during (d) the considered event are in black. Surface of the bed visible in an image: $30 \mathrm{~cm} \times 25 \mathrm{~cm}$

The total area of grains in displacement during the pebble movement (Fig. 6d) represents a bedload flux approximately 3.5 times greater than the quantity of sediment transported before the threshold effect (Fig. 6c). This result lies between the range of coefficients 2.5-14 found in Fig. 5 for the samples B-2 and B-7, and confirms that these unexpected values of bedload transport are due to threshold effects. This type of event has not been clearly shown previously by the authors' knowledge.

For approximately 150 minutes of videos collected during the rising tide considered on B site, only two threshold effects were detected, indicating that such events are quite unusual. This leads us to depict (Fig. 7) the evolution of bedload rates without the discontinuities corresponding to the threshold effects observed in Fig. 5. 


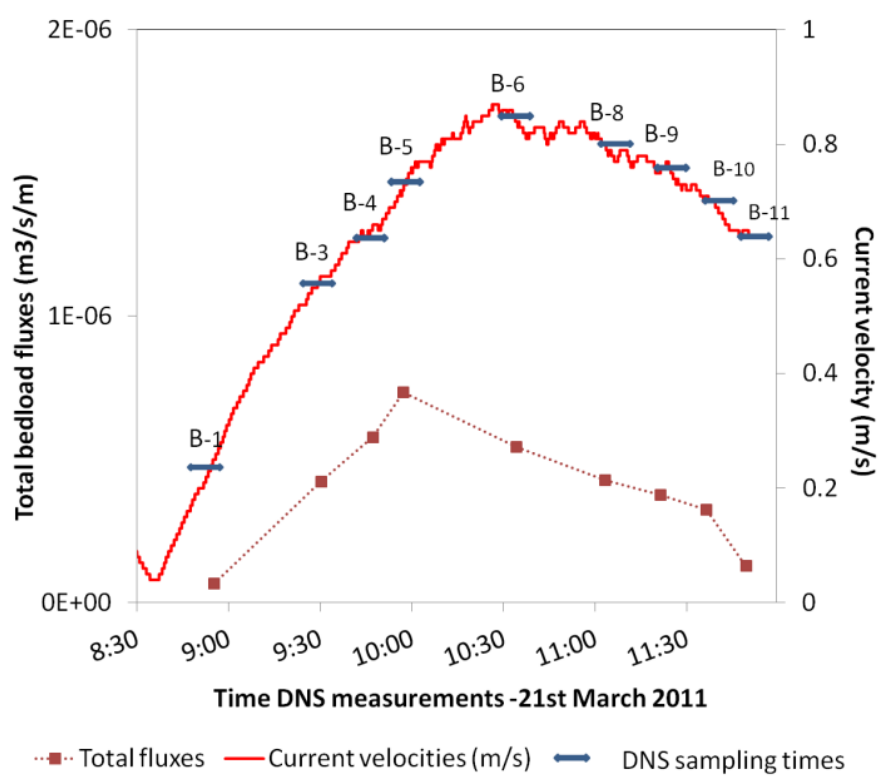

Fig. 7 Total bedload transport rates for the B site after extraction of the threshold effects

As threshold effects constitute a rare phenomenon not described in usual formulas of bedload transport, in the next sections, the measured fluxes are compared in the next sections to predicted ones without the two events observed.

4.2 Comparison between measured and predicted bedload fluxes using a single fraction approach

Most of formulas to estimate bedload transport are based on the excess of shear stress $\theta_{50}-$ $\theta_{c r, 50}$. Four models among the most commonly used are considered (Table 2).

Table 2 Bedload formulas using a single fraction approach

\begin{tabular}{lll}
\hline Formulation & Total bedload dimensionless flux & Validity range \\
\hline $\begin{array}{l}\text { Meyer-Peter-Muller } \\
\text { (MPM, 1948) }\end{array}$ & $\Phi_{\mathrm{b}}=8\left(\theta_{50}-\theta_{c r, 50}\right)^{\frac{3}{2}}$ & $0.4<\mathrm{D}_{50}<29 \mathrm{~mm}$ \\
\hline $\begin{array}{l}\text { Van Rijn } \\
\text { (VR, 1984) }\end{array}$ & $\Phi_{\mathrm{b}}=\left\{\begin{array}{l}0.053 \mathrm{D}_{* 5}^{-0.3} \mathrm{~T}_{50}^{2.1} \text { if } \mathrm{T}_{50}<3 \\
0.1 \mathrm{D}_{* 50}^{-0.3} \mathrm{~T}_{50}^{1.5}\end{array}\right.$ if $\mathrm{T}_{50} \geq 3$ & $0.2<\mathrm{D}_{50}<2 \mathrm{~mm}$ \\
\hline Nielsen (1992) & $\mathrm{T}_{50}=\frac{\tau_{b}-\tau_{c r, 50}}{\tau_{c r, 50}}$ & $0.69<\mathrm{D}_{50}<28.7 \mathrm{~mm}$ \\
\hline Ribberink (1998) & $\Phi_{\mathrm{b}}=12\left(\theta_{50}-\theta_{c r, 50}\right) \sqrt{\theta_{50}}$ & $0.4<\mathrm{D}_{50}<29 \mathrm{~mm}$ \\
\hline
\end{tabular}

In the present work, the median diameter $\mathrm{D}_{50}$ needs to be extracted from a bed layer representative of the availability of sediments exposed to the flow. As the surface layer collected by divers (from 0 to $2 \mathrm{~cm}$ depth) is located in the active layer of the A and B sites (section 3.1), the grain sizes found in this layer are used to estimate the initial bed material composition. The resulting values for $\mathrm{D}_{50}$ are used in the formulas presented in Table 2. Fig. 8 
presents the comparison between measured and predicted bedload transport fluxes where $\mathrm{R}$ is a discrepancy ratio given by:

$$
R=\frac{\Phi_{\mathrm{b}, \text { predicted }}}{\Phi_{\mathrm{b}, \mathrm{DNS} \text { measured }}}
$$
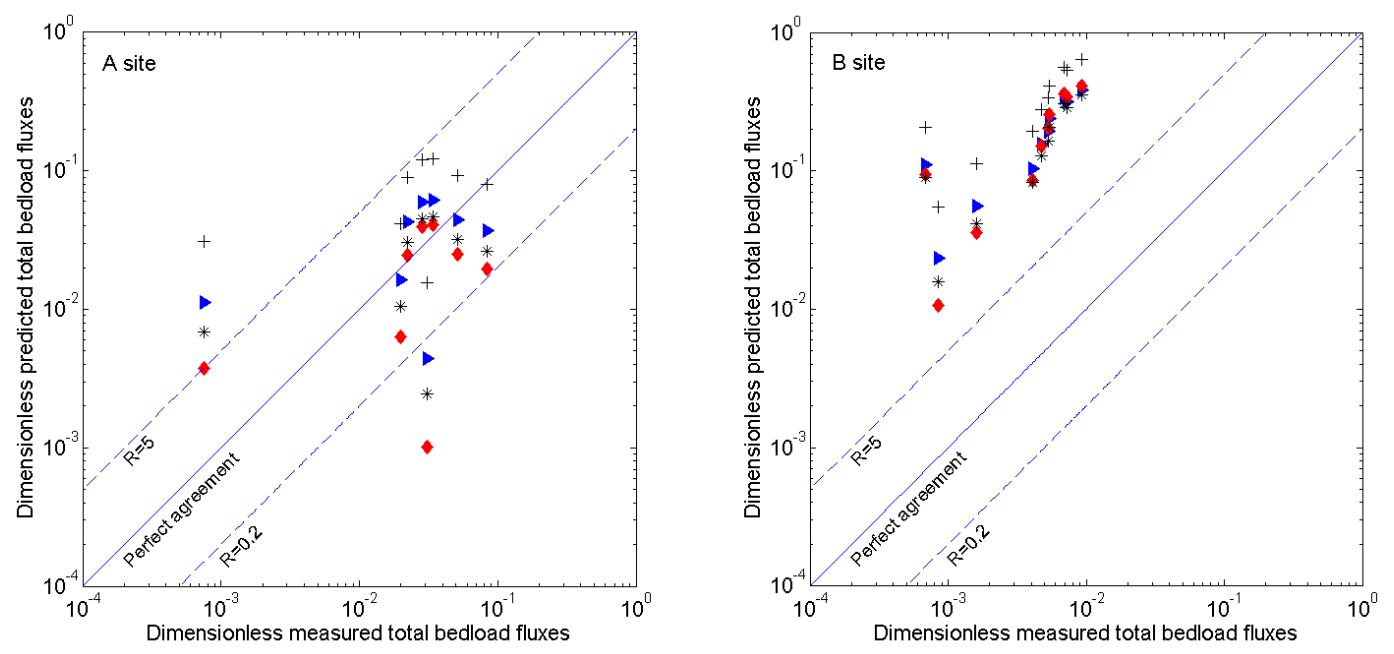

- Meyer-Peter-Muller (1948) - Van Rijn (1984) + Nielsen (1992) * Ribberink (1998)

Fig. 8 Comparison between predicted and measured dimensionless total bedload rates

There is a reasonable agreement for the A site between measured and predicted fluxes as we get $0.2<\mathrm{R}<5$ for most of the data. However, for the graded sediments of site B, predicted fluxes are found to be significantly higher than measured ones. Similarly to our results, Kleinhans \& Van Rijn [19] have also reported a trend of models to overpredict total bedload transport compared to their flume data.

In the present study, the surface layer of both sites displays approximately the same median diameter, while the grains size distributions are widely different. As the formulas tested in this section involved only a single grain size $\left(\mathrm{D}_{50}\right)$, they fit well the data obtained on the A site, where well sorted sediments are present (section 3.1). However, the agreement between estimated and measured values of total bedload fluxes is not satisfactory for the B site, as size dispersed sediments lie on the bed. Consequently, a multiple fraction approach, which takes into account the size gradation of the bed by considering each size fraction separately, is considered in the next section for this B site.

\subsection{Comparison between measured and predicted bedload fluxes using a multiple fraction} approach

Some well-known specific processes to graded sediments have been implemented in single fraction equations to represent the interactions between different size classes of particles on the bed. Thus, the formulas of MPM [26], VR [43] and Ribberink [32] have been adapted for multiple grain size fractions transport. In this section, the formula of $\mathrm{Wu}$ et al. [50] is also tested. Wu et al. developed a semi-empirical formula to estimate dimensionless fractional bedload rates from flume experiments and alluvial rivers data. The formula is recommended for a median diameter between $0.2 \mathrm{~mm}$ and $50 \mathrm{~mm}$ and for a standard deviation between 1.28 
and 9.91, which correspond to our field conditions. Present results for the B site are plotted in Fig. 9 with the predicted values given by the multi-fraction formulations of Table 3 .

Table 3 Bedload formulas using a multiple-fraction approach

\begin{tabular}{|c|c|c|}
\hline Formulation & Fractional bedload dimensionless flux & Involved parameters \\
\hline MPM (1948) & $\Phi_{\mathrm{b}, \mathrm{i}}=8 \mathrm{p}_{\mathrm{i}} \mathrm{H}_{\mathrm{f}}\left(\theta_{i}-\xi_{i} \theta_{c r, i}\right)^{3 / 2}$ & \\
\hline $\begin{array}{l}\text { VR (1984) } \\
\text { Kleinhans \& Van } \\
\text { Rijn (2002) }\end{array}$ & $\Phi_{\mathrm{b}, \mathrm{i}}=\mathrm{p}_{\mathrm{i}} \mathrm{H}_{\mathrm{f}}\left\{\begin{array}{lll}0.053 \mathrm{D}_{* \mathrm{i}}^{-0.3} \mathrm{~T}_{\mathrm{i}}^{2.1} & \text { if } & \mathrm{T}_{\mathrm{i}}<3 \\
0.1 \mathrm{D}_{* \mathrm{i}}^{-0.3} \mathrm{~T}_{\mathrm{i}}^{1.5} & \text { if } & \mathrm{T}_{\mathrm{i}} \geq 3\end{array}\right.$ & $\begin{array}{l}\mathrm{T}_{\mathrm{i}}=\frac{\tau_{b}-\tau_{c r, i, \text { corrected }}}{\tau_{c r, i}} \\
\tau_{c r, i}=\left(\rho_{s}-\rho\right) g D_{i} \theta_{c r, i} \\
\tau_{c r, i, \text { corrected }}=\xi_{i} \frac{D_{i}}{D_{50}} \tau_{c r, 50}\end{array}$ \\
\hline Ribberink (1998) & $\Phi_{\mathrm{b}, \mathrm{i}}=10.4 \mathrm{p}_{\mathrm{i}} \mathrm{H}_{\mathrm{f}}\left(\theta_{i}-\xi_{i} \theta_{c r, i}\right)^{1.67}$ & \\
\hline Wu et al. (2000) & $\Phi_{\mathrm{b}, \mathrm{i}}=0.0053 \mathrm{p}_{\mathrm{i}} \mathrm{H}_{\mathrm{f}}\left(\frac{\tau_{b}}{\tau_{c r, i}}-1\right)^{2.2}$ & $\begin{array}{l}\tau_{c r, i}=\theta_{c r, i}\left(\frac{p_{e i}}{p_{m i}}\right)^{-0.6}\left(\rho_{s}-\rho\right) g D_{i} \\
p_{e i}=\sum_{j=1}^{N} p_{e i, j}=\sum_{j=1}^{N} p_{b j} \frac{d_{i}}{d_{i}+d_{j}} \\
p_{m i}=\sum_{j=1}^{N} p_{m i, j}=\sum_{j=1}^{N} p_{b j} \frac{d_{j}}{d_{i}+d_{j}} \\
\theta_{c r, i}=0.03\end{array}$ \\
\hline
\end{tabular}

In Table 3, $p_{i}$ is the proportion of each size class in the bed composition and $D_{i}$ is the median particle diameter of the size class $i$ in the surface layer from 0 to $2 \mathrm{~cm}$ depth. The formulation of the Shields parameter in a multiple fraction approach is given by:

$$
\theta_{\mathrm{i}}=\frac{\mathrm{u}_{*}^{2}}{(\mathrm{~s}-1) \mathrm{gD}_{\mathrm{i}}}
$$

The critical Shields number is provided by Soulsby [41]:

$$
\theta_{\mathrm{cr}, \mathrm{i}}=\frac{0.3}{1+1.2 \mathrm{D}_{*, \mathrm{i}}}+0.055\left(1-\exp \left(-0.02 \mathrm{D}_{*, \mathrm{i}}\right)\right)
$$

where

$$
\mathrm{D}_{*, \mathrm{i}}=\left(\frac{(\mathrm{s}-1) \mathrm{g}}{\gamma^{2}}\right)^{1 / 3} \mathrm{D}_{\mathrm{i}}
$$

The hiding-exposure factor $\xi_{\mathrm{i}}$ of Egiazaroff [10] and the hindrance factor $\mathrm{H}_{\mathrm{f}}$ of Kleinhans and Van Rijn [19] are applied.

$$
\xi_{i}=\left[\frac{\log (19)}{\log \left(19 \frac{D_{i}}{D_{50}}\right)}\right]^{2}
$$




$$
\mathrm{H}_{\mathrm{f}}=1-\exp \left(-7.2\left(\frac{\mathrm{D}_{90, \text { bedload predicted }}}{\mathrm{D}_{90, \text { bed }}}\right)^{2}\right)
$$

$D_{90, b e d}$ is easily extracted from granulometries of the surface layers, represented on Fig. 3. The average measured value of $D_{90, \text { bedload }}$ given by the DNS samples is used instead of a predicted value. We get $\mathrm{H}_{\mathrm{f}}=0.47$ for the $\mathrm{B}$ site $\left(\mathrm{H}_{\mathrm{f}}=1\right.$ for the A site). The fractional discrepancy ratio $R_{i}$ are estimated with Eq. 16 and summarized in Table 4.

$$
R_{i}=\frac{\Phi_{\mathrm{b}, \mathrm{i}, \text { predicted }}}{\Phi_{\mathrm{b}, \mathrm{i}, \mathrm{DNS} \text { measured }}}
$$
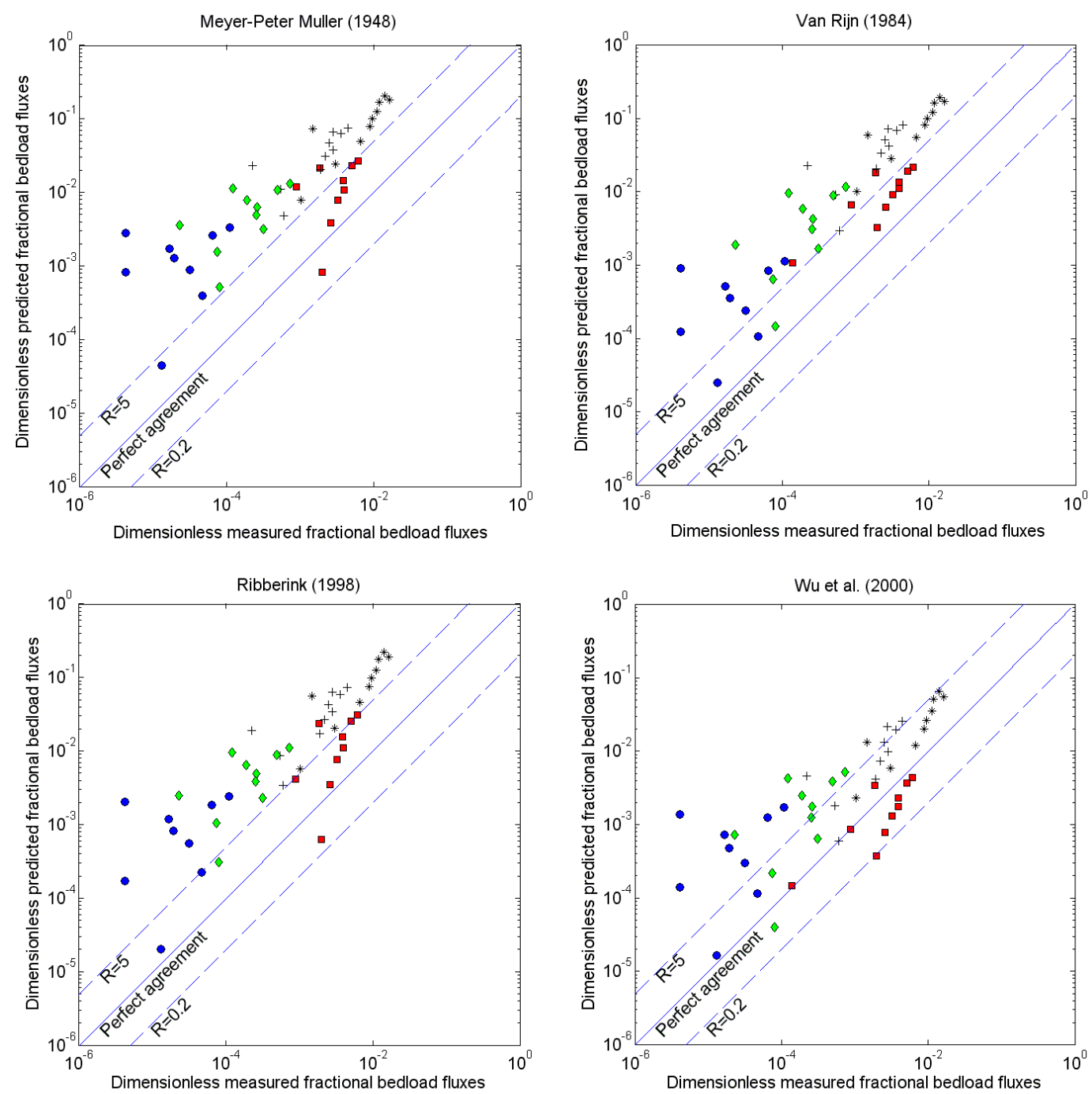

- Fine Sand * Medium Sand + Coarse Sand $\bullet$ Very Coarse Sand • Granules

Fig. 9 Comparison of predicted and measured dimensionless fractional bedload rates (B site) 
Table 4 Values of the fractional discrepancy ratios $\mathrm{R}_{\mathrm{i}}$ for the considered multiple fractional formulas

\begin{tabular}{lllll}
\hline & MPM & VR & Ribberink & Wu et al. \\
Fine Sand $(0.125-0.25 \mathrm{~mm})$ & 5 & 4.6 & 4.3 & 0.7 \\
Medium Sand $(0.25-0.5 \mathrm{~mm})$ & 14.3 & 13.6 & 12.5 & 3.6 \\
Coarse Sand $(0.5-1 \mathrm{~mm})$ & 24.8 & 24.9 & 21.2 & 5.8 \\
Very Coarse Sand $(1-2 \mathrm{~mm})$ & 41.3 & 27.1 & 31.7 & 11.2 \\
Very Fine Granule $(2-4 \mathrm{~mm})$ & 128.5 & 33.5 & 81.9 & 53.3 \\
\hline
\end{tabular}

Fig. 9 and Table 4 show that the formulation proposed by $\mathrm{Wu}$ et al. [50], which was originally developed for graded sediments, provides a better agreement with present tests than the other models. However, even for this model, present results display differences between predicted and measured fluxes. The discrepancy ratio increases with the particles size and significant divergences appear for very coarse sand and very fine granules. In other words, a physical process not taken into account in the MF approach may contribute to explain the observed discrepancies. Let us consider the effect of particle shape on bedload transport.

\subsection{The effect of particle shape on bedload transport}

In order to better characterize the grain shape, images of particles composing the surface layer (from 0 to $2 \mathrm{~cm}$ depth) and images of particles transported by bedload (DNS samples) are carried out with a Nikon D300S camera of 4288x2848 pixels resolution. Grains are placed on a white paper sheet to accentuate the contrast between the object (the grains) and the background. A special attention is paid to separate the different grains on pictures to make easier the images post-processing [16]. The camera, mounted on a tripod, is positioned above the grains. Two neon lamps are placed on each side of the camera to avoid shading effects on large particles. Following the recommendations of Rodriguez et al. [33], fine sands are not considered as their small size (less than 800 pixels $^{2}$ ) can generate large errors in the estimation of shape factors. Thus, four fractions are studied, from medium sand to very fine granules, and at least 250 particles of each fraction are analyzed to get statistically relevant results. Colored images are converted into binary pictures with the ImageJ software following the process described by Janaka et al. [16]. The following 2D shape coefficients (Fig. 10) are calculated for each particle: the circularity index (CI), the roundness index (RI) and the elongation index (EI).

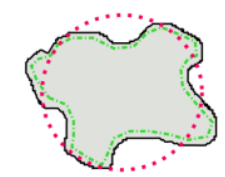

Circularity index

Area of the particle

$$
\text { Perimeter }
$$

. Circle of equivalent area

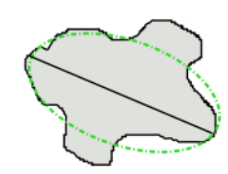

Roundness index

Area of the particle Fitting ellipse

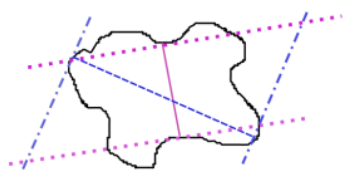

Elongation index

- Feret min

--- Feret max

-.. $\quad$ \} Limits of the bounding box

Fig. 10 Grain shape factors

$$
\mathrm{CI}=\frac{4 \pi \mathrm{A}}{\mathrm{P}^{2}} \quad \mathrm{RI}=\frac{4 \mathrm{~A}}{\pi \cdot{\text { major }- \text { axis }^{2}}^{2}} \quad \mathrm{EI}=\frac{\text { Feret } \min }{\text { Feret } \max }
$$


where $A$ is the particle area, $P$ the grain perimeter, major_axis the major axis of an ellipse fitting the dimensions of the grain, Feret min the minimum dimension of the 2D-particle and Feret max the maximum dimension.

The circularity index $(C I)$ can be defined as the deviation from a perfect circle $(C I=1)$. It is affected by the form, the symmetry but also the roughness of the grain while the roundness index $(R I)$ is a measure of the surface roughness independent of the overall form of the particles. The elongation index $(E I)$ is defined as the ratio between the two principal axes of the particle. The proportion of particles with a given shape factor is estimated with Eq. 18-19 for each size class in the different samples.

$$
\begin{gathered}
\mathrm{p}_{\mathrm{i}, \mathrm{f}, \text { surface }}=\frac{\mathrm{N}_{\mathrm{i}, \mathrm{f} \text {,surface }}}{\mathrm{N}_{\mathrm{i}} \text {,surface }} \\
\mathrm{p}_{\mathrm{i}, \mathrm{f} \text {,transported }}=\frac{\mathrm{N}_{\mathrm{i}, \mathrm{f} \text {,transported }}}{\mathrm{N}_{\mathrm{i}} \text {,transported }}
\end{gathered}
$$

Bedload sediment fluxes for the different size and shape fractions are calculated with the following equation:

$$
\mathrm{q}_{\mathrm{si,f}}=\frac{\mathrm{G}_{\mathrm{i}, \mathrm{f}}}{\rho b \mathrm{bt}} \cdot \frac{1}{\mathrm{p}_{\mathrm{i}, \mathrm{f}, \text { surface }}}
$$

where $G_{i, f}$ is the transported particles mass of the size class i and the shape class $\mathrm{f}$ :

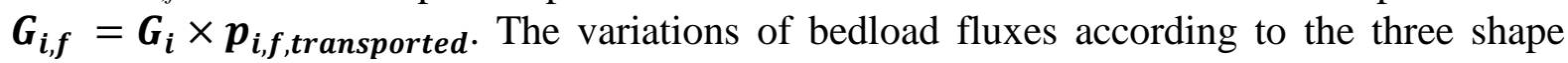
factors described are depicted in Fig. 11 for granules.
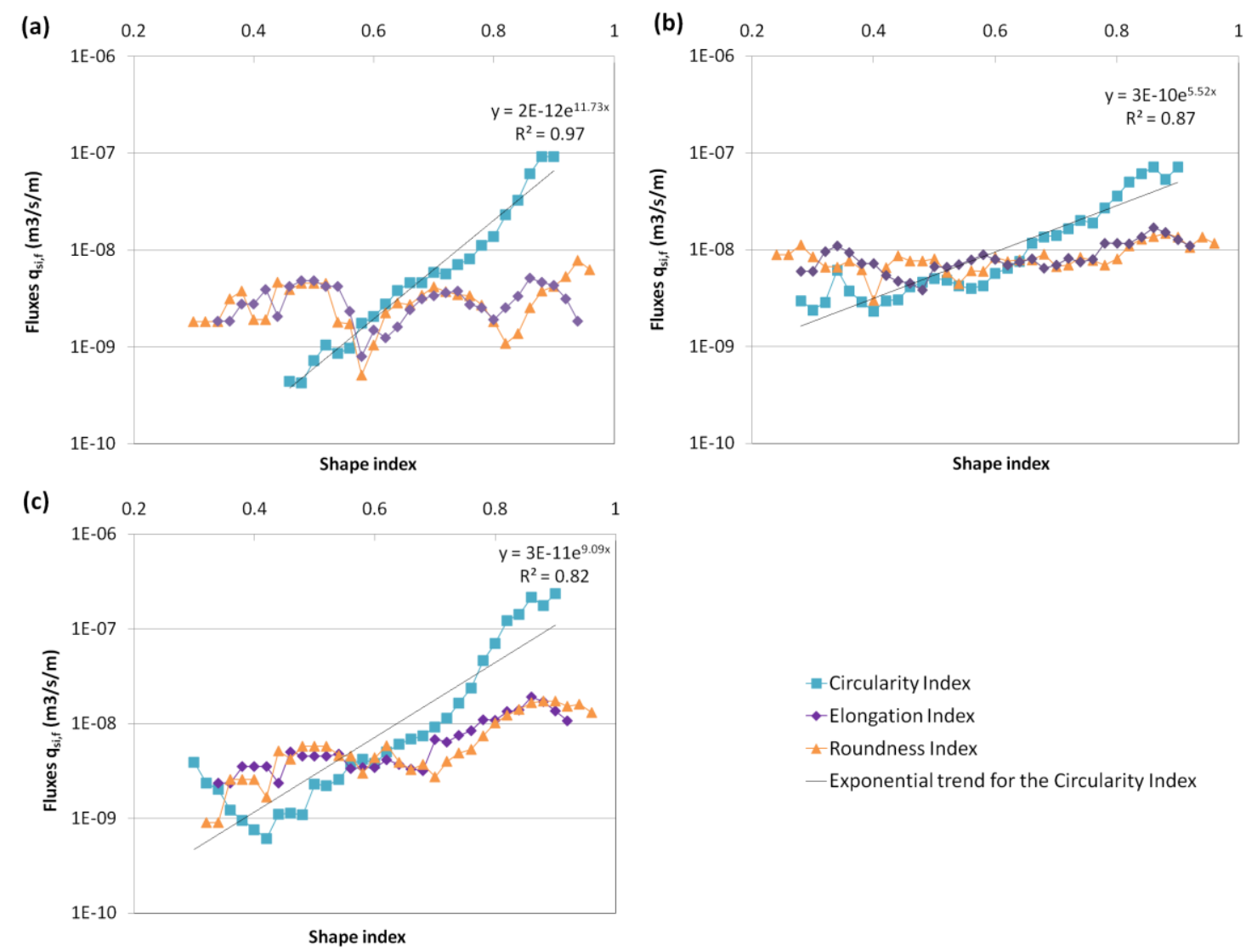

Fig. 11 Variation of bedload fluxes with grain shape descriptors for very fine granules (2-4 mm) - (a) B-1 sample (Fig. 7; $U=0.24 \mathrm{~m} / \mathrm{s})$; (b) B-3 sample (U=0.57 m/s); (c) B-8 sample $(\mathrm{U}=0.80 \mathrm{~m} / \mathrm{s})$ 
Fig. 11 shows that the roundness and elongation indexes do not significantly affect bedload transport as fluxes are almost constant for all the coefficients values. However, for the very fine granules size class, bedload transport clearly appears to increase for increasing values of the circularity coefficient. The exponential trends exhibited in Fig. 11 for the fluxes variations according to the circularity index are estimated with the least square method.

As the circularity index is the most discriminating factor found, the following figures are focused on this coefficient for the four size classes considered, from medium sands to very fine granules. In Fig. 12, each graphic represents a size class and contains four distributions of circularities: the one of the surface layer collected by divers, which represent the proportion of sediments available for transport on the bed for each circularity index range, and three for the DNS samples already mentioned in Fig. 11.

(a)

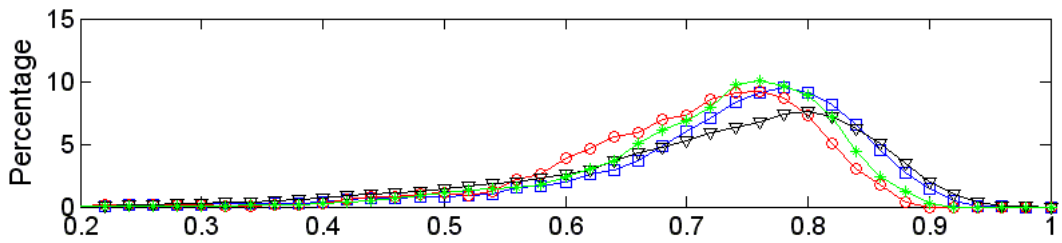

(b)

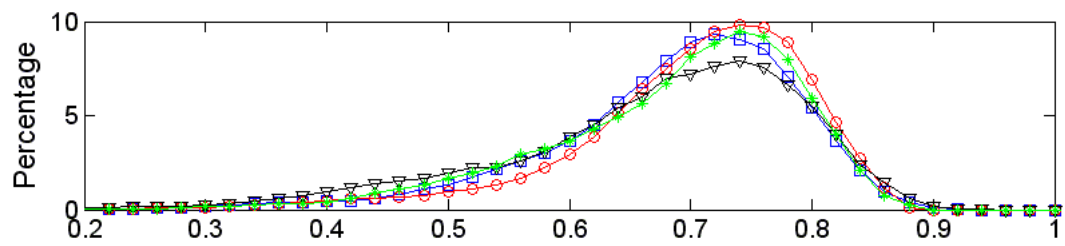

(c)

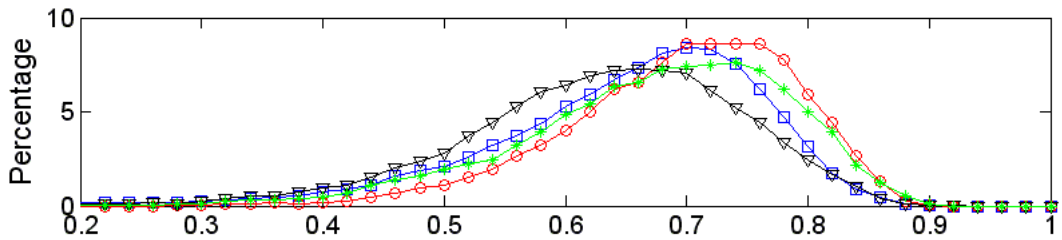

(d)

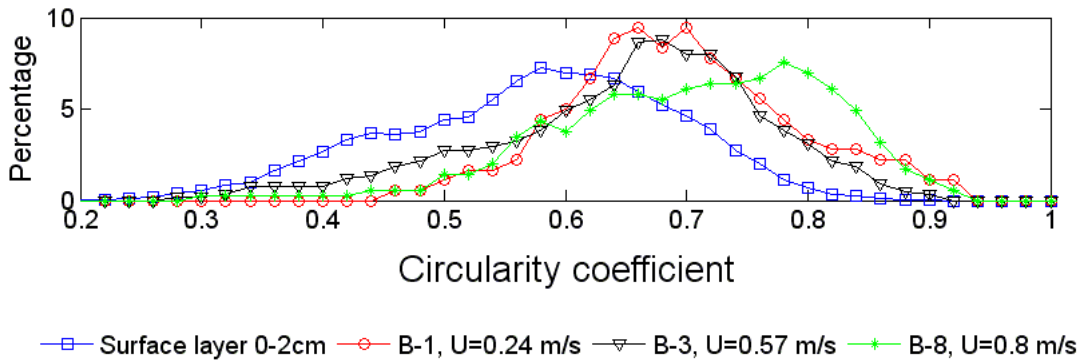

Fig. 12 Comparison of circularity index distributions between the surface layer and three DNS samples; (a) Medium sand $(0.25-0.5 \mathrm{~mm})$; (b) Coarse sand $(0.5-1 \mathrm{~mm})$; (c) Very coarse sand $(1-2 \mathrm{~mm})$; (d) Granules (2-4 $\mathrm{mm})$

By considering the medium sand size class in Fig. 12, the circularity distributions of grains transported by bedload follow the same trend that the surface layer one. Consequently, the influence of the circularity index on the transport of this size class is not visible. However, a shift between the surface distribution and the DNS samples appears for coarse sand, very coarse sand and granules, and increases with increasing values of particles diameter. This result, which transcribes a selective entrainment of the most circular particles of the bed is confirmed by Fig. 13 in which the variation of the median circularity $\mathrm{C}_{\mathrm{i}, 50}$ is plotted, per size class, relatively to the median particle diameter $D_{i, 50}$ for the surface layer (sediment 
availability) and for all the DNS samples.

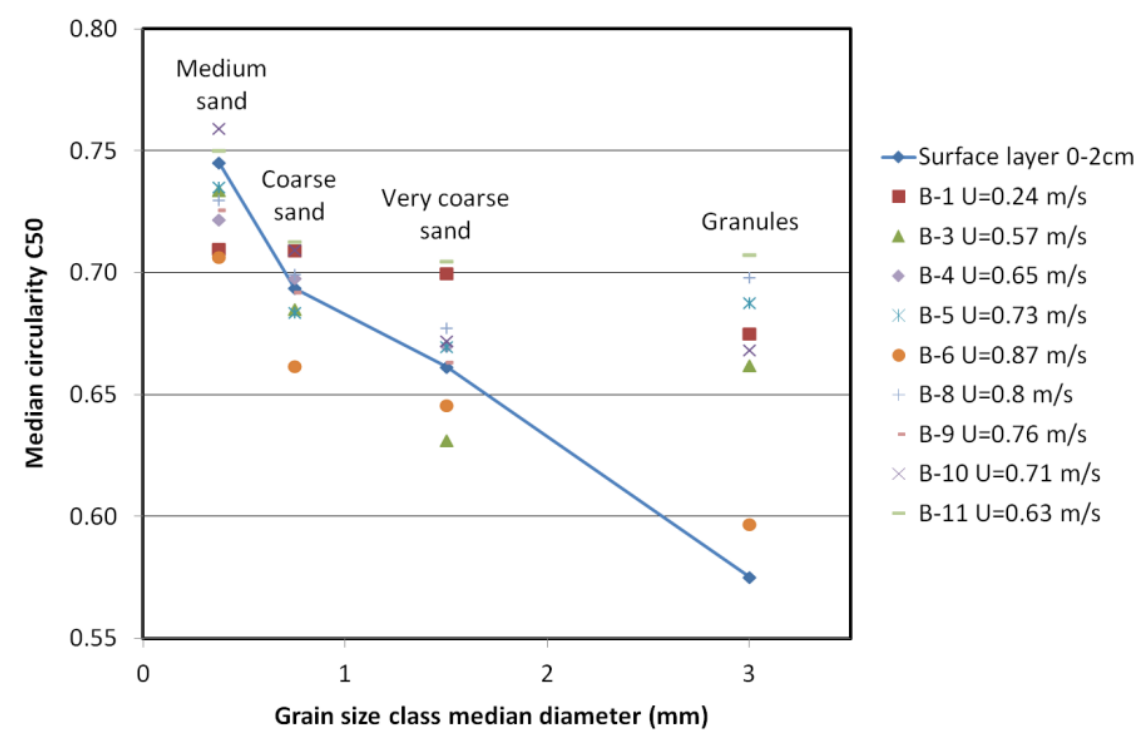

Fig. 13 Variation of the median circularity $C_{50, i}$ with the median particle diameter $D_{i}$ per fraction

A significant decrease, in the surface layer, of the median circularity $\mathrm{C}_{\mathrm{i}, 50}$ for increasing values of $D_{i, 50}$ is highlighted in Fig. 13. Furthermore, the mean circularities of the DNS samples gets further and further away from the reference layer $C_{i, 50}$ for increasing values of $\mathrm{D}_{\mathrm{i}, 50}$, validating a preferential transport particles more circular than the average circularity of the grains present on the bed. As particle shape is not considered in bedload formulas for a fractionwise approach, it can partially explain the differences observed between predicted and measured fluxes (Fig. 9).

In order to take into account the effect of particle shape for bedload transport estimation, we propose to substitute in Wu et al.'s formula [50] the particles median diameter by a length characterizing both particles size and circularity: $D_{i, 50} / \sqrt{ } C_{i, 50}$. In this new parameter, the square root is introduced as the circularity index is related to an area.

Komar and $\mathrm{Li}[20,24]$ explained that elongated grains in a mixture of sediments are imbricated and consequently less easily transported than spheres. Otherwise, Allen [1], by studying the fall velocity on single particles in water, confirmed that the drag coefficient was smaller for spherical grains. By analogy, we can assume that circular grains in a mixture of different shapes are more exposed to the current than other particles. Following this reasoning, the proposed coefficient is introduced in the critical shear stress and a new formula is obtained.

$$
\Phi_{\mathrm{b}, \mathrm{i}}=0.0053 \mathrm{p}_{\mathrm{i}} \mathrm{H}_{\mathrm{f}}\left(\frac{\tau_{b}}{\theta_{c r, i}\left(\frac{p_{e i}}{p_{m i}}\right)^{-0.6}\left(\rho_{s}-\rho\right) g \frac{D_{i, 50}}{\sqrt{c_{i, 50}}}}-1\right)^{2.2}
$$

Fig. 14 and Table 5 depict the comparison between the adjusted Wu et al.'s model and the present data. 

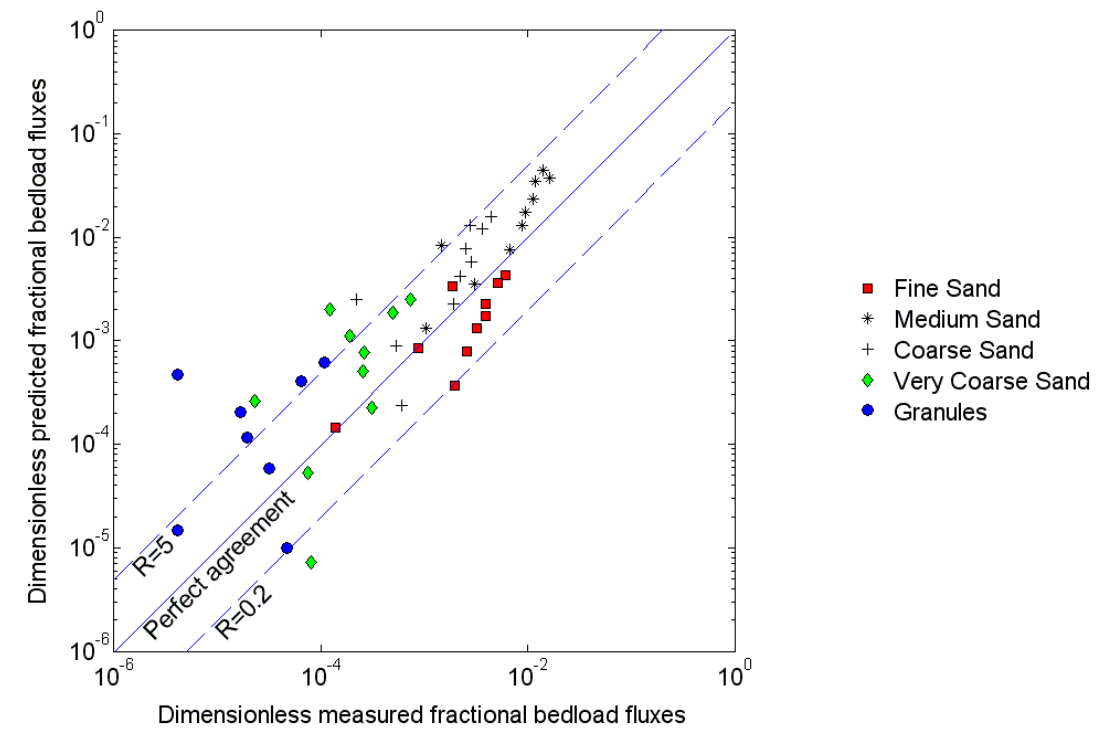

Fig. 14 Comparison of measured and predicted (adjusted Wu et al. model) dimensionless fractional bedload rates

Table 5 Values of the fractional discrepancy ratio for the Wu et al. original and adjusted formulae

\begin{tabular}{lll}
\hline & Wu et al. & $\begin{array}{l}\text { Adjusted Wu } \\
\text { et al.'s formula }\end{array}$ \\
\hline Fine Sand $(0.125-0.25 \mathrm{~mm})$ & 0.7 & 0.7 \\
Medium Sand $(0.25-0.5 \mathrm{~mm})$ & 3.6 & 2.3 \\
Coarse Sand $(0.5-1 \mathrm{~mm})$ & 5.8 & 3.3 \\
Very Coarse Sand $(1-2 \mathrm{~mm})$ & 11.2 & 4.8 \\
Very Fine Granule $(2-4 \mathrm{~mm})$ & 53.3 & 14.9 \\
\hline
\end{tabular}

Table 5 clearly shows that the proposed adjustment improves the bedload transport estimations from medium sand to granules size classes. The efficiency of this adjustment gains strength for increasing values of particle size as the grain circularity index significantly decreases for high size classes diameters (Fig. 13).

\section{Conclusions}

In this paper, the bedload transport variability along a tidal cycle is studied on two sites characterized by a flat seabed subjected to tidal currents without waves. The first site displays a uniform granulometry while the second one shows a strong heterometric facies. The collection of bedload discharges is carried out with a Delft Nile Sampler [13,44] and the sediment mobility on the bed is visualized with the DySPI system $[2,4]$. In order to compare the in-situ bedload rates found with the predictions of classical bedload formulas, the sediment availability on the bed is deduced from samples of the bottom, collected by divers during the slack period immediately before DNS and DySPI measurements.

A single fraction approach to estimate total bedload rates with the median diameter $\mathrm{D}_{50}$ in the formulas of MPM [26], VR [43], Nielsen [28] and Ribberink [32] provides good results for the uniform environment studied, but is not adapted to graded sediments. A fractionwise approach, with the use of the hindrance factor proposed by Kleinhans and Van Rijn [19] and the hiding/exposure factor of Egiazaroff [10] in the formula of Wu et al. [50], is found to get 
more reliable results. However, some discrepancies still remain, especially for granules.

Present results reveal that taking into account the sediment shape can improve the prediction of bedload transport for heterogeneous sediments in size. Furthermore, among the three shape descriptors considered (elongation, roundness and circularity), only the circularity appears to have a significant effect on bedload fluxes. An adjustment of the Wu et al. bedload formula [50], based on the introduction of a length characterizing both the particle size and circularity is proposed. It gives a significant improvement of the efficiency of the formula for graded sediments.

Finally, the shape of the particles is characterized from pictures that deliver 2D information on particles. Future research is necessary to study the impact of the third dimension on bedload transport through the analysis of the flatness index of particles or by the realization of flume experiments with different particles shape.

Acknowledgements The authors express their sincere thanks to the High Normandy region (Scale Research Network) for funding this work and to the University of Utrecht and Ifremer for the loan of the DNS and the DySPI respectively. The authors extend their thanks to Olivier Blanpain for his help on DySPI videos processing and as a member of the team on board of the research vessel Côtes de la Manche (INSU/CNRS), composed also of Michel Lunven, Erwan Legall, Philippe Cugier and Pascal Bailly du Bois, who made the field data collection possible during the campaign.

\section{References}

1. Allen JRL (1984) Experiments on the settling, overturning and entrainment of bivalve shells and related models. Sedimentology 31: 227-250

2. Balasubramanian S, Voropayev S.I, Fernando H.J.S (2008) Grain sorting and decay of sand ripples under oscillatory flow and turbulence. Journal of Turbulence, $9,1$.

3. Blanpain O, Bailly du Bois P, Cugier P, Lafite R, Lunven M, Dupont J, Le Gall E, Legrand J, Pichavant P (2009) Dynamic Sediment Profile Imaging (DySPI): a new field method for the study of dynamic processes at the sediment-water interface. Limnology and Oceanography: Methods 7: 8-20

4. Blanpain O (2009) Dynamique sédimentaire multiclasse : de l'étude des processus à la modélisation en Manche. PhD Thesis, Université de Rouen, France

5. Brown CB (1950) Sediment Transport. Engineering Hydraulics, Ch. 12, Rouse H, Wiley Edition

6. Chu T.D, Jarno-Druaux A, Marin F, Ezersky A.B (2012) Particles trajectories and size sorting above a rippled bed under standing water waves. Physical Review E, Vol. 85, N 2.

7. Cotton P, Carter DJT, Allan TD, Challenor PG, Woolf D, Wolf J, Hargreaves JC, Flather RA, Bin L, Holden N, Palmer D (1999) Joint Evaluation of Remote Sensing Information for Coastal And Harbour Organisations (JERICHO). British National Space Centre: 38

8. Demir T (2000) The influence of particle shape on bedload transport in coarse-bed river channels. Durham theses, Durham University

9. Durafour M, Jarno A, Le Bot S, Blanpain O, Lafite R, Marin F (2013) In-situ study of the influence of size and shape of sediments on bedload transport. $7^{\text {th }}$ Conference on Coastal Dynamics. Arcachon, France, pp 541-552

10. Egiazaroff IV (1965) Calculation of non-uniform sediment concentrations. Journal of the Hydraulics Division, ASCE, Vol 91, No. HY4, 225-248

11. Einstein HA (1942) Formulae for transportation of bed-load. Trans. ASCE, 107: 561-577

12. Engelund F, Hansen E (1967) A monograph on sediment transport in alluvial streams. Teknisk Forlag, Copenhagen, Denmark

13. Gaweesh MTK, Van Rijn LC (1994) Bed-load sampling in sand-bed rivers. Journal of Hydraulic Engineering, Vol. 120, Paper $\mathrm{N}^{\circ} 7492$

14. Hirano M (1970) On the river bed degradation downstream of a dam and the armoring phenomena. Proc. 14th Conference on Hydraulics

15. James JWC, Coggan RA, Blyth-Skyrme VJ, Morando A, Birchenough SNR, Bee E, Limpenny DS, Verling E, Vanstaen K, Pearce B, Johnston CM, Rocks KF, Philpott SL, Rees HL (2007) Eastern English Channel Marine Habitat Map. Sci. Ser. Tech Rep., Cefas Lowestoft, 139: 191pp

16. Janaka GHA, Kumara J, Kimitoshi Hayano, Keita Ogiwara (2012) Image Analysis Techniques on 
Evaluation of Particle Size Distribution of Gravel. International Journal of GEOMATE, Vol. 3, No. 1 (S1. No. 5), pp. 290-297

17. Jouanneau N, Sentchev A, Dumas F (2013) Numerical modelling of circulation and dispersion processes in Boulogne-sur-Mer harbour (Eastern English Channel): sensitivity to physical forcing and harbour design. Ocean Dynamics 63: 1321-1340

18. Kirchner JW, Dietrich WE, Iseya F, Ikeda H (1990) The variability of critical shear stress, friction angle, and grain protrusion in water-worked sediments. Sedimentology, 37: 647-672

19. Kleinhans MG, Van Rijn LC (2002) Stochastic prediction of sediment transport in sand-gravel bed rivers. Journal of Hydraulic Engineering, 128:4, 412-425

20. Komar PD, Li Z (1986) Pivoting analyses of the selective entrainment of sediments by shape and size with application to gravel threshold. Sedimentology, 33: 425-436

21. Lane EW, Carlson EJ (1954) Some observations on the effect of particle shape on the movement of coarse sediments. Transaction, American Geophysical Union, 35: 453-462

22. Larsonneur C, Vaslet D, Auffret JP (1978) Map of the surficial sediments of the English Channel. BRGM, Orléans, France

23. Lazure P \& Dumas F (2008) An external-internal mode coupling for a 3D hydrodynamical model for applications at regional scale (MARS). Advances in Water Ressources, 31: 233-250

24. Li Z, Komar PD (1986) Laboratory measurements of pivoting angles for applications to selective entrainment of gravel in a current. Sedimentology, 33: 413-423

25. Mantz PA (1977) Incipient transport of fine grains and flakes by fluids - extended Shields diagram. Journal of the Hydraulics Division, ASCE, Vol. 103, No. HY6, 601-615

26. Meyer-Peter E and Müller R (1948) Formulas for bed-load transport. Proceedings of the 2nd Congress rivers, International Association for Hydraulic Research, Rotterdam, the Netherlands, 39-64

27. Molinas A, Wu BS (1998) Effect of size gradation on transport of sediment mixtures. J. Hydraul. Eng. 124(8), 786-793

28. Nielsen P (1992) Coastal Bottom Boundary Layers and Sediment Transport. World Scientific

29. Paphitis D, Collins MB, Nash LA, Wallbridge S (2002) Settling velocities and entrainment thresholds of biogenic sands (shell fragments) under unidirectional flow. Sedimentology, 49: 211-225

30. Parker G, Klingeman PC, McLean DG (1982) Bedload and Size Distribution in Paved Gravel-Bed Streams. Journal of the Hydraulics Division, ASCE, Vol. 108, No. 4: 544-571

31. Prager EJ, Southard JB, Vivoni-Gallart ER (1996) Experiments on the entrainment threshold of wellsorted and poorly sorted carbonate sands. Sedimentology, 43: 33-40

32. Ribberink JS (1998) Bed-load transport for steady flows and unsteady oscillatory flows. Coastal Engineering, 34: 59-82

33. Rodriguez J, Johansson J, Edeskär, T (2012) Particle shape determination by two-dimensional image analysis in geotechnical engineering. Proceedings of Nordic Conference on Soil Mechanics and Geotechnical NGM, p. 207-218

34. Rousseaux G, Caps H, and Wesfreid J.-E (2004) Granular size segregation in underwater sand ripples. Eur.Phys. J. Ser. E. 13, pp. 213-219.

35. Schmidt HK, Ergenzinger P (1992) Bedload entrainment travel lengths, step lengths, rest periods studied with passive (iron, magnetic) and active (radio) tracer techniques. Earth Surface Processes and Landforms, 17,147-165

36. Schmidt HK, Gintz D (1995) Results of bedload tracer experiments in a mountain river. River Geomorphology. In Hickin, E.J. (Ed.) River Morphology. John Wiley \& Sons Ltd, Chichester

37. Shields AF (1936) Application of similarity principles and turbulence research to bed-load movement. Hydrodynamics Laboratory, California Institute of Technology, Publication $\mathrm{N}^{\circ} 167.43 \mathrm{pp}$

38. Smart GM, Jaeggi MNR (1983) Sediment transport on steep slopes. Mitteilungen der Versuchsanstalt für Wasserbau, Hydrologie und Glaziologie, Nr. 64, Zürich, 1983

39. Smith DA, Cheung KF (2003) Settling characteristics of calcareous sand. Journal of Hydraulic Engineering-ASCE, Vol. 129, 479-483

40. Smith DA, Cheung KF (2004) Initiation of Motion of Calcareous Sand. Journal of Hydraulic Engineering, Vol. 130(5), 467-472

41. Soulsby RL (1997) Dynamics of marine sands. Thomas Telford, Springfield, 249 pp

42. Sündermann J (1986) Landolt-Börnstein: Numerical Data and Functional Relationships in Science and Technology, Group V, Volume 3a. Springer-Verlag, Berlin, Germany

43. Van Rijn LC (1984) Sediment transport, Part I: Bed load transport. ASCE J. Hydraulic Engineering, 110: $1431-1456$

44. Van Rijn LC, Gaweesh MTK (1992) New total sediment-load sampler. Journal of Hydraulic 


\section{Engineering, Vol. 118, Paper $\mathrm{N}^{\circ} 2876$}

45. Van Rijn LC (2007) Unified view of sediment transport by currents and waves I: Initiation of motion, bed roughness and bedload transport. Journal of Hydraulic Engineering-ASCE, Vol. 133 (6), 649-667

46. Van Rijn LC (2007) Unified view of sediment transport by currents and waves III: Graded beds. Journal of Hydraulic Engineering-ASCE, Vol. 133 (7), 761-775

47. Velegrakys AF, Michel D, Collins MB, Lafite R, Oikonomou EK, Dupont JP, Huault MF, Lecouturier M, Salomon JC, Bishop C (1999) Sources, sinks and resuspension of suspended particulate matter in the eastern English Channel. Continental Shelf Research, Vol.19, Issues 15-16, 1933-1957

48. Wentworth C.K (1922) A scale of grade in class terms for clastic sediments. Journal of Geology Vol. 30, 377-392.

49. Wilcock P, Crowe J (2003) Surface-based Transport Model for Mixed-Size Sediment. Journal of Hydraulic Engineering, 129(2), 120-1284

50. Wu W, Wang SSY, Jia Yafei (2000) Nonuniform sediment transport in alluvial rivers. Journal of Hydraulic Research, 38:6, 427-434 